Supplementary Information for

\title{
Lanthanum doping enabling high drain current modulation in a p-type tin monoxide thin-film transistor
}

Sungyeon Yim ${ }^{1}$, Taikyu Kim ${ }^{1}$, Baekeun Yu ${ }^{1}$ Xu Hongwei ${ }^{1}$, Yong Youn ${ }^{2}$, Seungwu Han ${ }^{2}$, and Jae Kyeong Jeong ${ }^{1}$

${ }^{1}$ Department of Electronic Engineering, Hanyang University, Seoul 04763, South Korea

${ }^{2}$ Department of Materials Science and Engineering, Seoul National University, Seoul 08826, Korea

AUTHOR EMAIL ADDRESS: J. K. Jeong (jkjeong1@hanyang.ac.kr) 
(a)

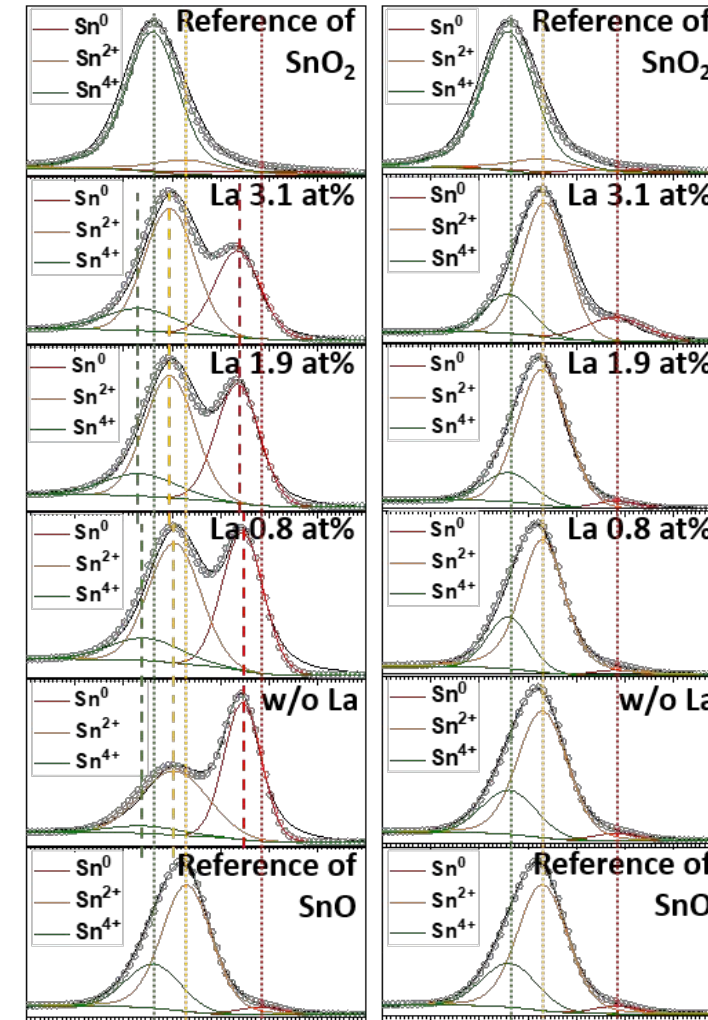

$\begin{array}{llllllllllllllll}489 & 488 & 487 & 486 & 485 & 484 & 483 & 48489 & 488 & 487 & 486 & 485 & 484 & 483 & 4\end{array}$ (c)

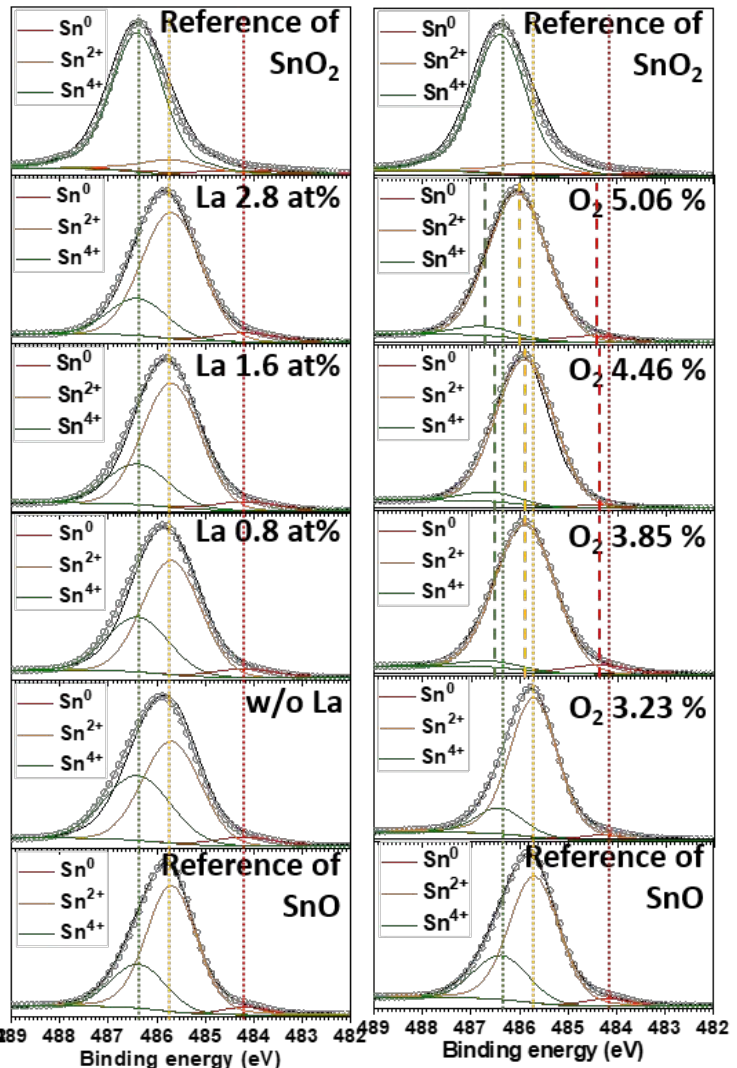

Figure S1. XP spectra of $\mathrm{Sn} 3 \mathrm{~d}_{5 / 2}$ for the $\mathrm{SnO}$ films with different La loadings (a) before PDA, (b) after PDA at $250{ }^{\circ} \mathrm{C}$, and (c) after PDA at $300{ }^{\circ} \mathrm{C}$. (d) XP spectra of Sn $3 \mathrm{~d}_{5 / 2}$ for the SnO films with different oxygen pressure on 1.9 at $\%$ loadings after PDA at $250{ }^{\circ} \mathrm{C}$. 

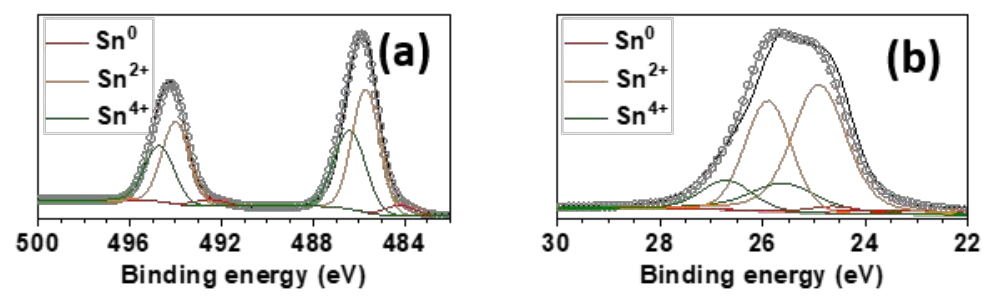

Figure S2. XP spectra of (a) Sn 3d and (b) Sn $4 d$ for the La-free $\mathrm{SnO}$ films post-annealed at $250{ }^{\circ} \mathrm{C}$ for $1 \mathrm{hr}$.

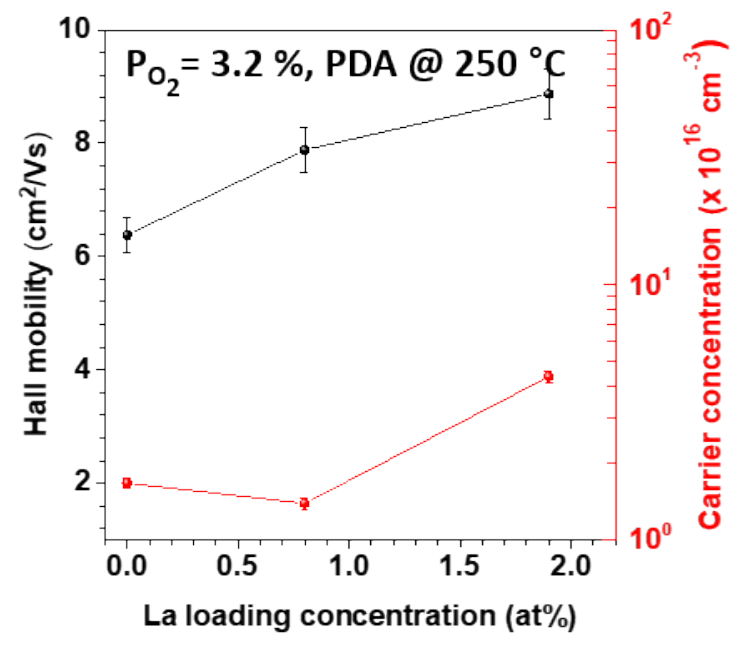

Figure S3. Electrical properties of $250{ }^{\circ} \mathrm{C}$ annealed $\mathrm{SnO}$ films with different La loadings from Hall effect measurement. Black line (left y-axis) is Hall mobility, and red line (right y-axis) is a free hole carrier concentration measured from Hall measurement. 


\section{S-4}


(a)

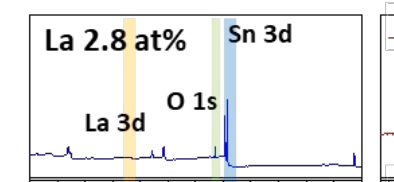

(b)

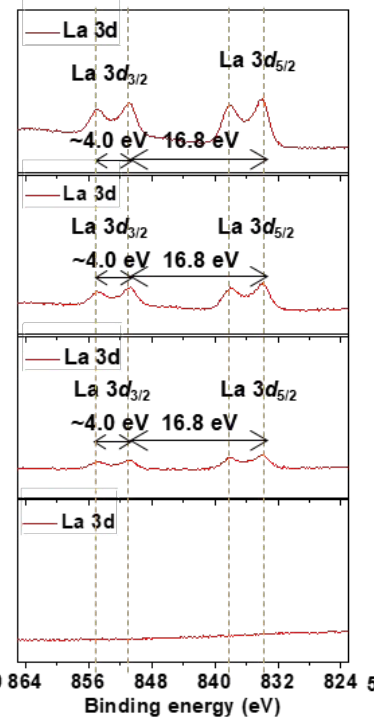

(c)

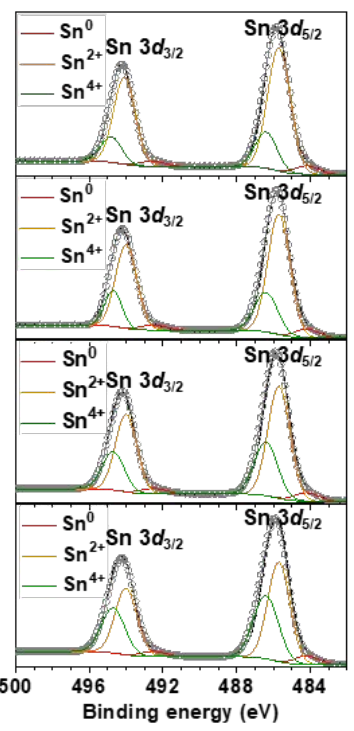

(d)

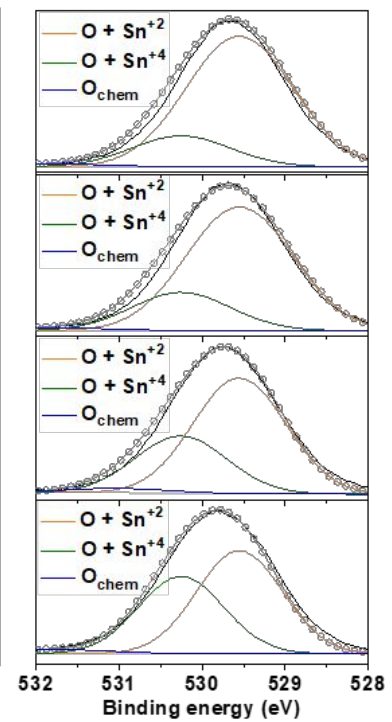

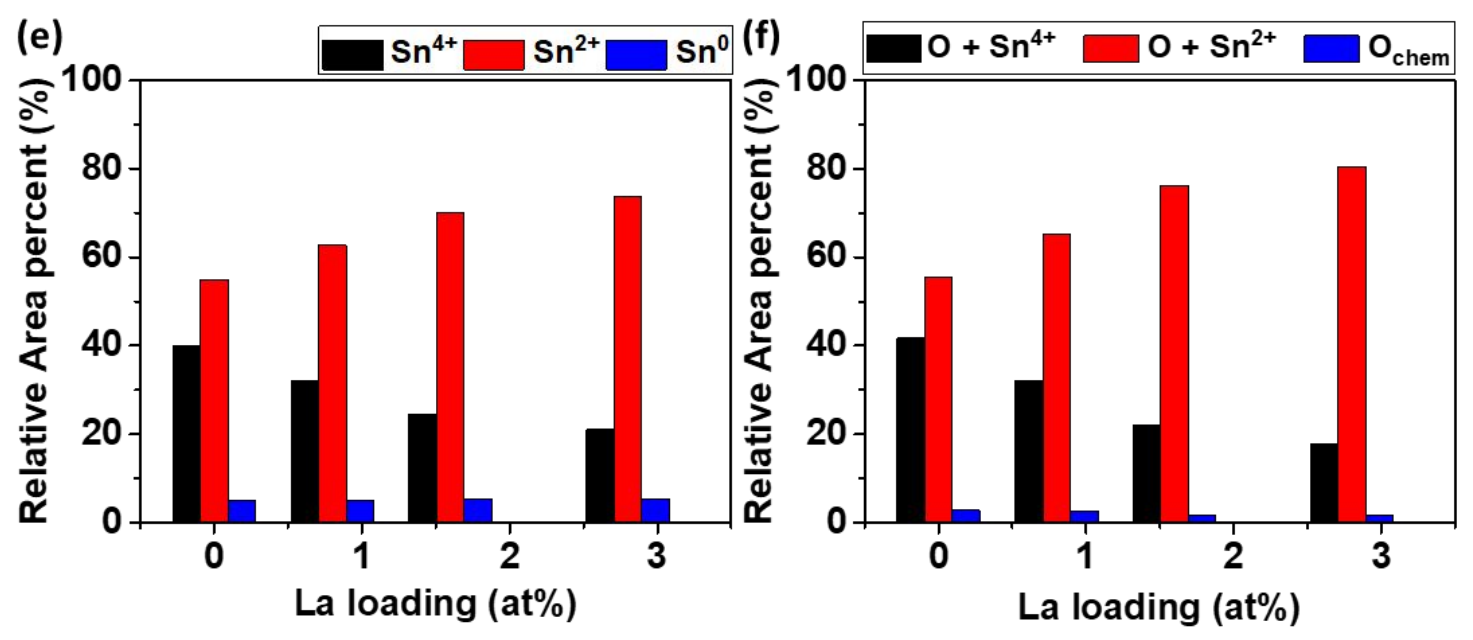

Figure S4. (a) XPS survey spectra, XP spectra of (b) La 3d, (c) Sn 3d, and (d) O 1s for the SnO films annealed in $300{ }^{\circ} \mathrm{C}$ with different La loadings. Chemical compositions including $\mathrm{Sn}^{0}, \mathrm{Sn}^{2+}$, and $\mathrm{Sn}^{4+}$ of SnO films with different La loadings, which were de-convoluted from XP spectra of (e) Sn 3d and (f) O 1s. 
(a)

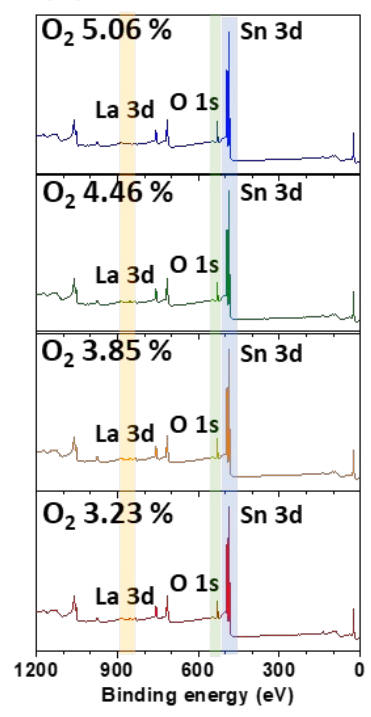

(b)

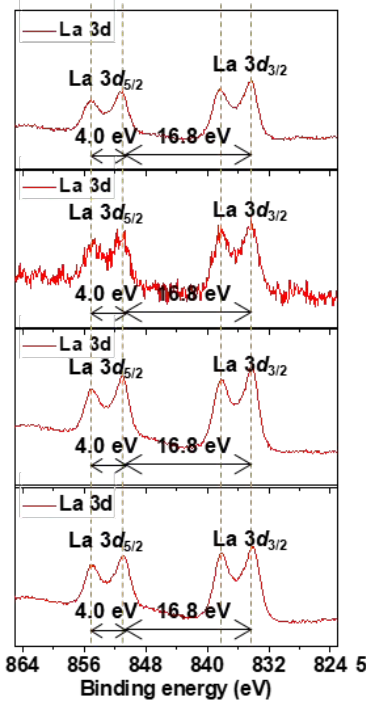

(c)

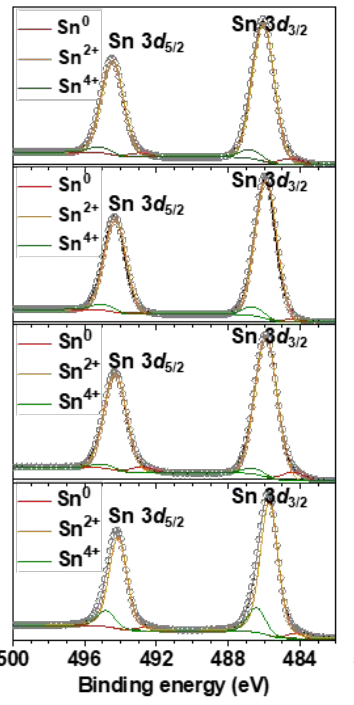

(d)

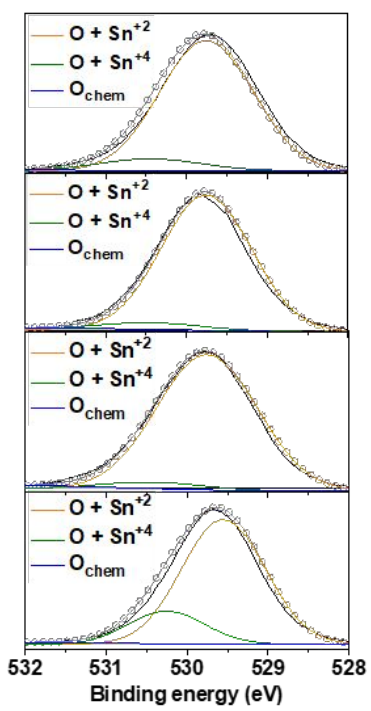

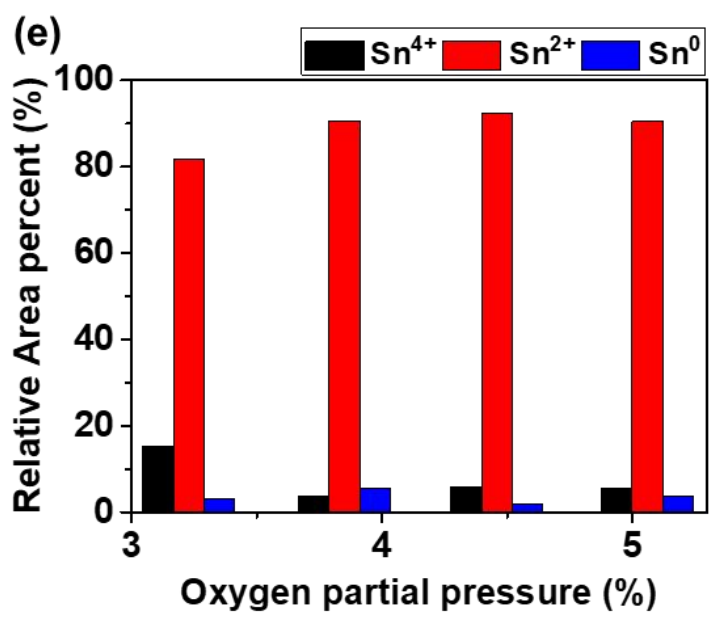

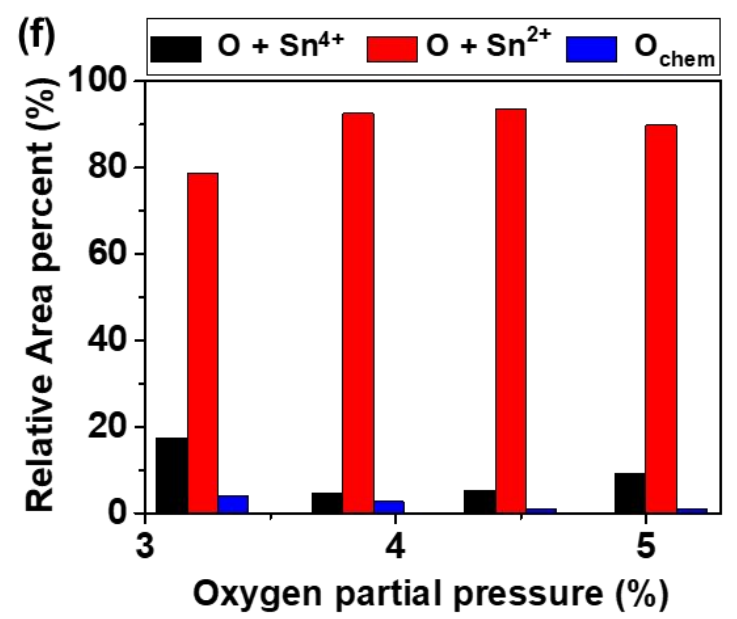

Figure S5. (a) XPS survey spectra, XP spectra of (b) La 3d, (c) Sn 3d, and (d) O 1s for the SnO films annealed at $250{ }^{\circ} \mathrm{C}$ with different oxygen pressure on 1.9 at\% loadings. Chemical compositions including $\mathrm{Sn}^{0}, \mathrm{Sn}^{2+}$, and $\mathrm{Sn}^{4+}$ of $\mathrm{SnO}$ films with different oxygen pressure on 1.9 at\% La loadings, which were de-convoluted from XP spectra of (e) Sn 3d and (f) O 1s. 

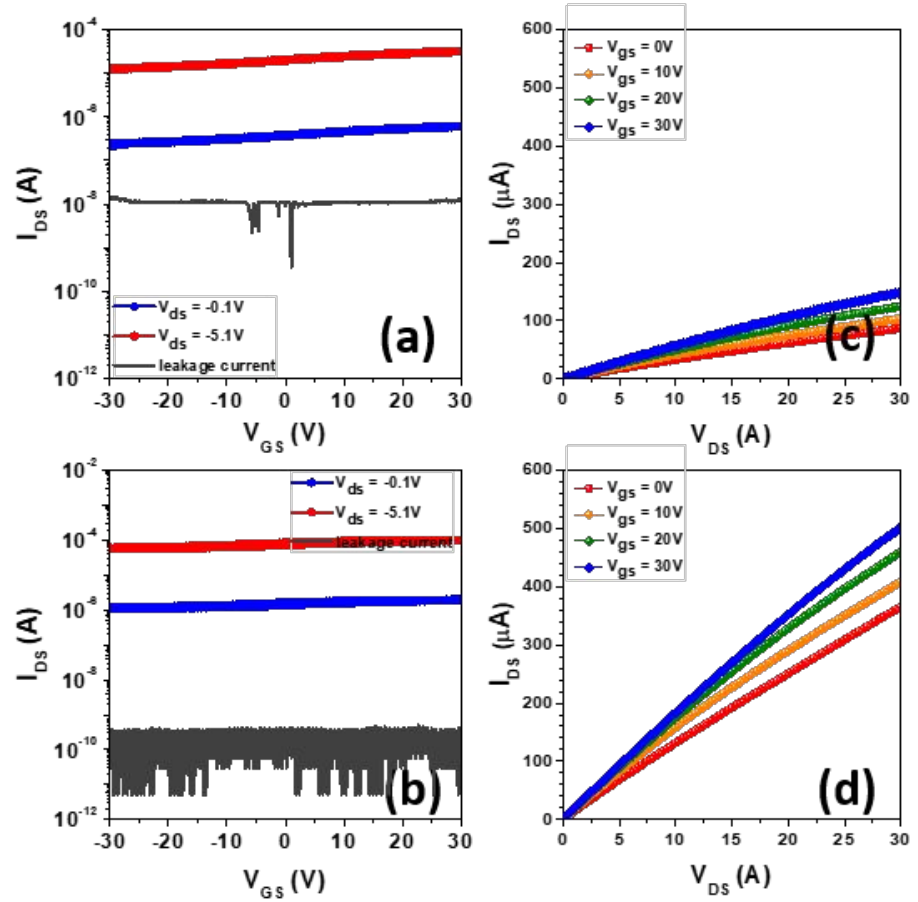

Figure S6. Transfer characteristics of the SnO TFTs with different La loadings of (a) 0 at $\%$ and (b) 1.9 at $\%$ after the PDA at $250{ }^{\circ} \mathrm{C}$ for $1 \mathrm{hr}$ under the forming gas atmosphere. The corresponding output characteristics of the SnO TFTs with different La loadings of (c) 0 at $\%$ and (d) 1.9 at $\%$. 
(a)

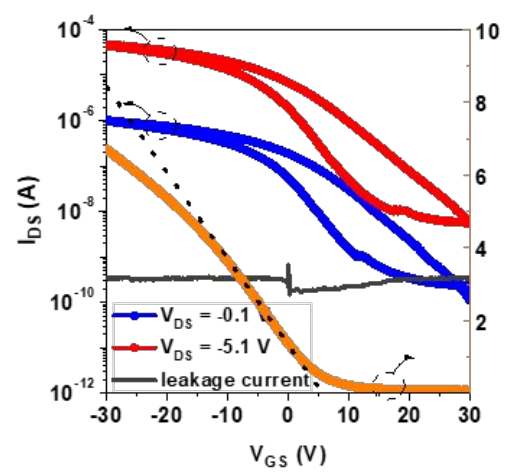

(b)

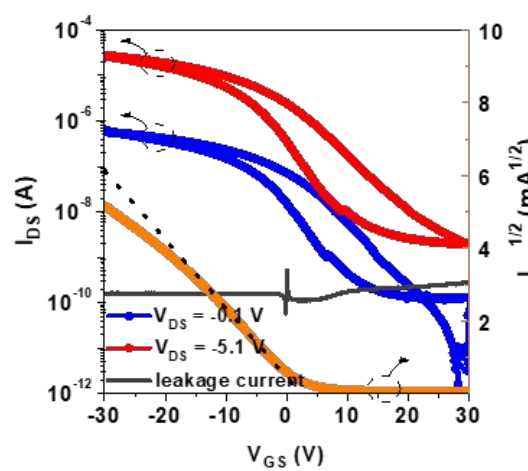

(c)

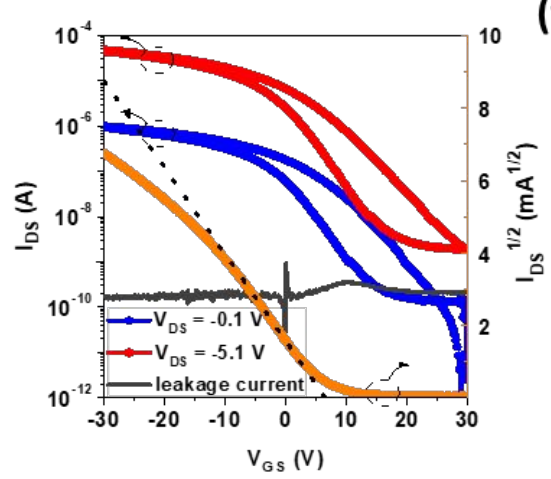

(d)

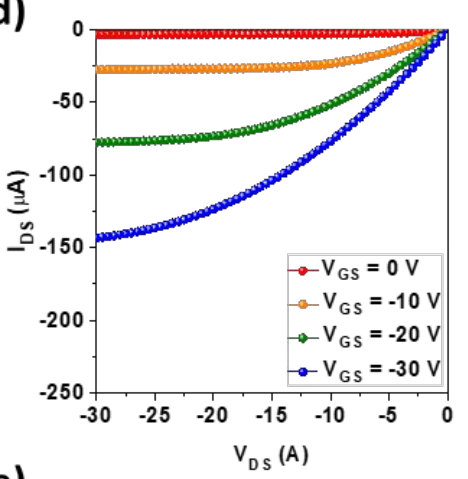

(e)

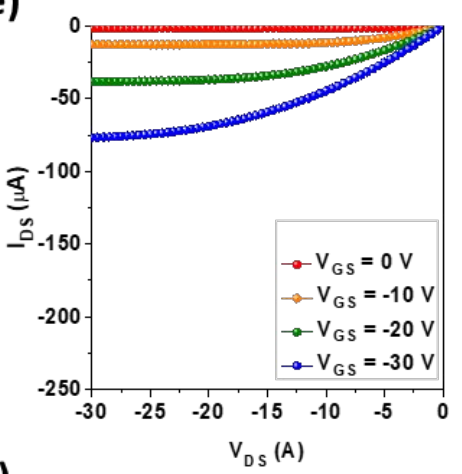

(f)

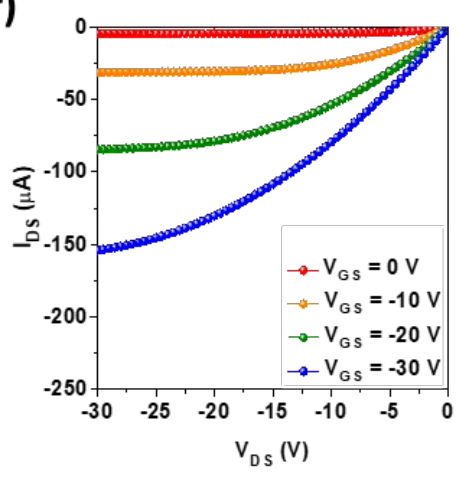

Figure S7. Transfer characteristics of the 1.9 at $\%$ La-loaded SnO TFTs annealed in $250{ }^{\circ} \mathrm{C}$ with different oxygen partial pressures of (a) $3.23 \%$, (b) 3.85 at $\%$, and (c) 4.46 at $\%$. The corresponding output characteristics of the 1.9 at $\%$ La-loaded SnO TFTs with oxygen partial pressures of (d) $3.23 \%$, (e) $3.85 \%$, and (f) $4.46 \%$. 

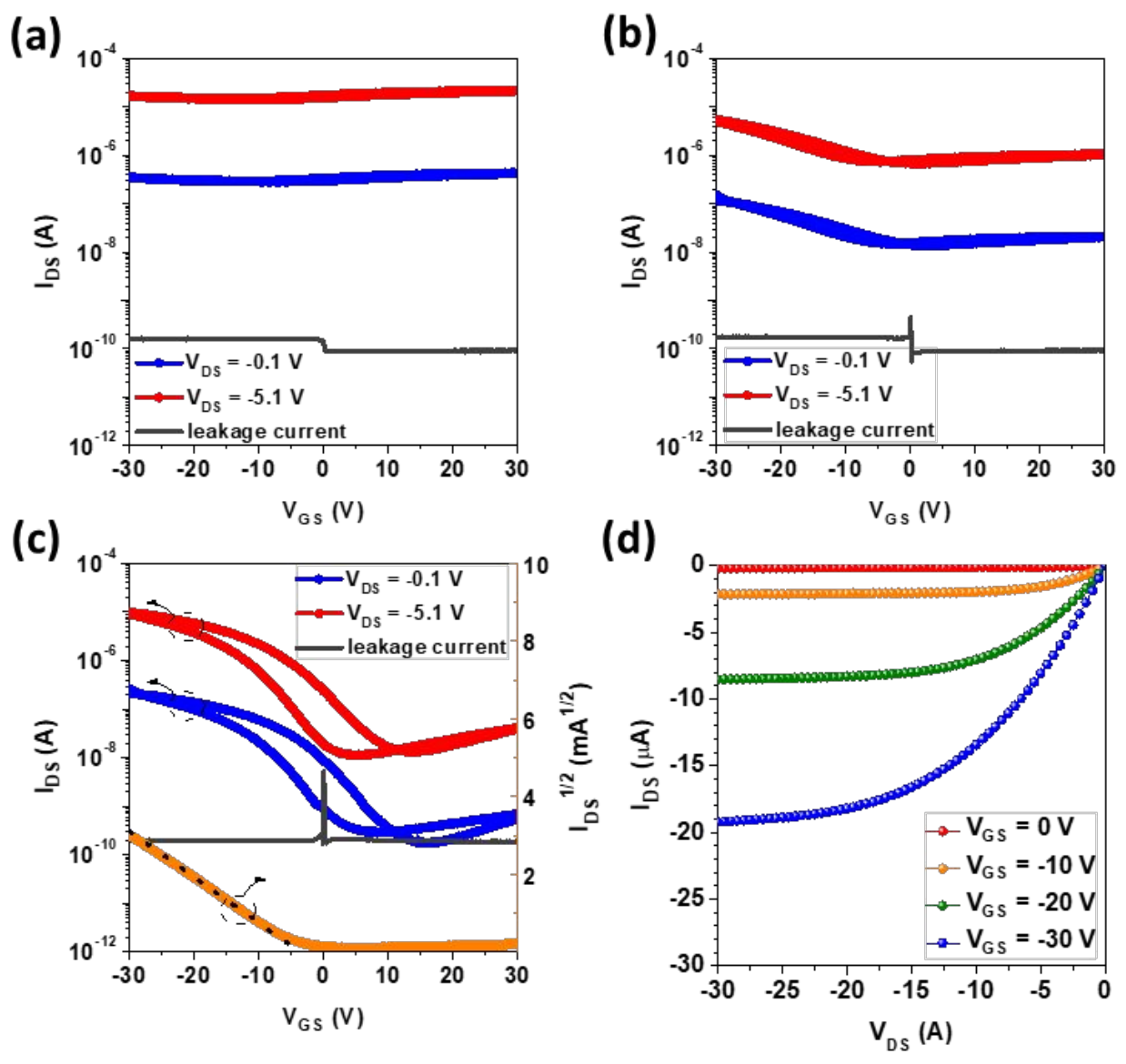

Figure S8. Transfer characteristics of the SnO TFTs annealed at $300{ }^{\circ} \mathrm{C}$ with different La loadings of (a) 0 at $\%$, (b) 0.8 at $\%$, and (c) 1.9 at $\%$. (d) The output characteristics of the SnO TFTs with 1.9 at $\%$ La loadings 


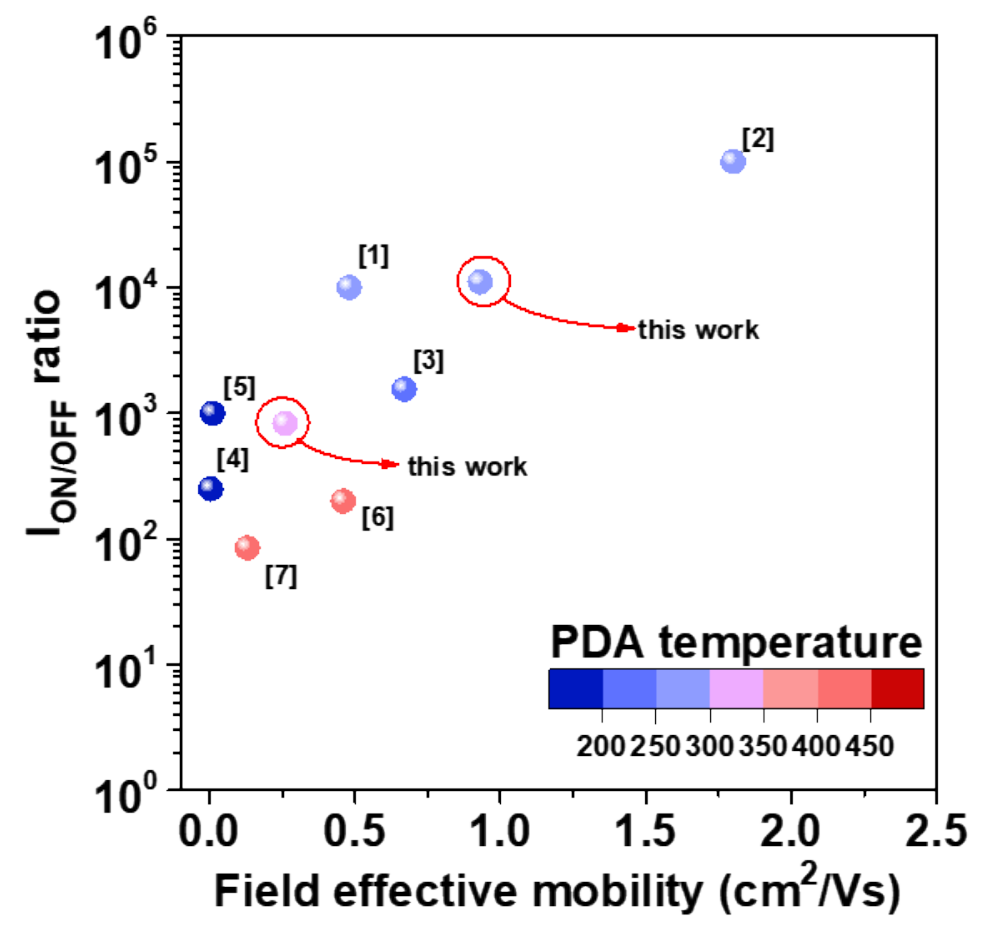

Figure S9. Comparisons of the trade-off between the saturation mobility and $\mathrm{I}_{\mathrm{ON} / \mathrm{OFF}}$ ratio for the $\mathrm{SnO}$ TFTs fabricated at the various annealing temperatures. For fair comparison, the SnO TFTs with $\mathrm{SiO}_{2}$ gate dielectric and non-passivated devices were collected. It can be shown that the performances of $\mathrm{SnO}$ TFTs reported in the literatures were deteriorated at the higher annealing temperature $\left(>300{ }^{\circ} \mathrm{C}\right)$ compared to those at the lower annealing temperature $\left(<300{ }^{\circ} \mathrm{C}\right)$. The introduction of La cation into the $\mathrm{SnO}$ channel allowed the resulting transistor to exhibit the higher mobility and $\mathrm{I}_{\mathrm{ON} / \mathrm{OFF}}$ ratio due to the La-induced efficient suppression of $\mathrm{Sn}^{4+}$, as shown in Figure 8b. 
Table S1. Chemical compositions including $\mathrm{Sn}^{0}, \mathrm{Sn}^{2+}$, and $\mathrm{Sn}^{4+}$ of the La-free $\mathrm{SnO}$ films post-annealed at $250{ }^{\circ} \mathrm{C}$ for $1 \mathrm{hr}$ states, which was de-convoluted from XP spectra of $\mathrm{Sn} 3 \mathrm{~d}_{5 / 2}$ and $\mathrm{Sn} 4 \mathrm{~d}_{5 / 2}$.

\begin{tabular}{c|ccc}
\hline XP Spectra & $\mathbf{S n}^{\mathbf{0}} \mathbf{( \% )}$ & $\mathbf{S n}^{2+}(\mathbf{\%})$ & $\mathbf{S n}^{4+}(\mathbf{\%})$ \\
\hline $\mathbf{S n} \mathbf{3 d} \mathbf{5}_{\mathbf{2}}$ & 3.8 & 70.9 & 25.3 \\
$\mathbf{S n ~} \mathbf{4} \mathbf{d}_{\mathbf{5} / \mathbf{2}}$ & 5.7 & 69.7 & 24.6 \\
\hline
\end{tabular}

Table S2. Chemical compositions including $\mathrm{Sn}^{0}, \mathrm{Sn}^{2+}$, and $\mathrm{Sn}^{4+}$ of as deposited $\mathrm{SnO}$ films with different La loadings, which were de-convoluted from XP spectra of Sn $3 \mathrm{~d}$ and O 1s.

\begin{tabular}{|c|c|c|c|c|c|c|}
\hline \multirow[b]{2}{*}{$\begin{array}{c}\text { La Loading } \\
\text { in SnO film } \\
\text { [at\%] }\end{array}$} & \multicolumn{3}{|c|}{ Sn 3d } & \multicolumn{3}{|c|}{ O 1s } \\
\hline & $\begin{array}{c}\mathrm{Sn}^{4+} \\
(486.8 \\
\pm \quad 0.1 \mathrm{eV})\end{array}$ & $\begin{array}{c}\mathrm{Sn}^{2+} \\
(486.1 \\
\pm \quad 0.1 \mathrm{eV})\end{array}$ & $\begin{array}{c}\mathrm{Sn}^{0} \\
(484.6 \\
\pm \quad 0.1 \mathrm{eV})\end{array}$ & $\begin{array}{c}\mathbf{O}_{\text {chem }} \\
(531.75 \\
\text { eV) }\end{array}$ & $\begin{array}{c}\mathrm{O}+\mathrm{Sn}^{4+} \\
(\mathbf{5 3 0 . 2 5} \\
\mathrm{eV})\end{array}$ & $\begin{array}{c}\mathrm{O}+\mathrm{Sn}^{2+} \\
(529.55 \\
\mathrm{eV})\end{array}$ \\
\hline 0 & 5.4 & 43.2 & 51.4 & 4.1 & 41.7 & 54.2 \\
\hline 0.8 & 11.7 & 46.1 & 42.2 & 4.5 & 38.8 & 56.7 \\
\hline 1.9 & 12.5 & 47.2 & 40.3 & 0.8 & 41.1 & 58.1 \\
\hline 3.1 & 13.7 & 53.0 & 33.3 & 4.4 & 34.0 & 61.6 \\
\hline
\end{tabular}

Table S3. Chemical compositions including $\mathrm{Sn}^{0}, \mathrm{Sn}^{2+}$, and $\mathrm{Sn}^{4+}$ of $\mathrm{SnO}$ films annealed at 250 ${ }^{\circ} \mathrm{C}$ with different La loadings, which were de-convoluted from XP spectra of $\mathrm{Sn} 3 \mathrm{~d}$ and $\mathrm{O} 1 \mathrm{~s}$.

\begin{tabular}{|c|c|c|c|c|c|c|}
\hline \multirow[b]{2}{*}{$\begin{array}{c}\text { La Loading } \\
\text { in SnO film } \\
\text { [at\%] }\end{array}$} & \multicolumn{3}{|c|}{ Sn 3d } & \multicolumn{3}{|c|}{ O 1s } \\
\hline & $\begin{array}{c}\mathrm{Sn}^{4+} \\
(486.4 \\
\pm \quad 0.3 \mathrm{eV})\end{array}$ & $\begin{array}{c}\mathrm{Sn}^{2+} \\
(485.7 \\
\pm \quad 0.3 \mathrm{eV})\end{array}$ & $\begin{array}{c}\mathrm{Sn}^{0} \\
(484.2 \\
\pm 0.3 \mathrm{eV})\end{array}$ & $\begin{array}{c}O_{\text {chem }} \\
(531.75 \\
\text { eV) }\end{array}$ & $\begin{array}{c}\mathrm{O}+\mathrm{Sn}^{4+} \\
(\mathbf{5 3 0 . 2 5} \\
\mathrm{eV})\end{array}$ & $\begin{array}{c}\mathrm{O}+\mathrm{Sn}^{2+} \\
(529.55 \\
\mathrm{eV})\end{array}$ \\
\hline 0 & 25.3 & 70.9 & 3.8 & 3.7 & 27.4 & 68.9 \\
\hline 0.8 & 23.4 & 74.2 & 2.4 & 3.8 & 23.1 & 73.1 \\
\hline 1.9 & 16.9 & 79.7 & 3.4 & 3.9 & 17.4 & 78.7 \\
\hline 3.1 & 19.2 & 65.4 & 15.4 & 3.1 & 33.7 & 63.2 \\
\hline
\end{tabular}


Table S4. Hall effect measurements for the SnO films with different La loadings of 0 and 1.9 at $\%$, which were annealed in forming gas atmosphere in $250{ }^{\circ} \mathrm{C}$.

\begin{tabular}{|c|c|c|c|}
\hline $\begin{array}{c}\text { La Loading } \\
\text { in SnO film [at\%] }\end{array}$ & $\begin{array}{c}\text { majority } \\
\text { carrier type }\end{array}$ & $\begin{array}{c}\mu_{\text {Hall }} \\
\left(\mathrm{cm}^{2} / \mathrm{Vs}\right)\end{array}$ & $\begin{array}{l}N_{\text {Hall }} \\
\left(\mathbf{c m}^{-3}\right)\end{array}$ \\
\hline 0 & electron & $1.2 \pm 0.9$ & $4.0( \pm 2.7) \times 10^{18}$ \\
\hline 1.9 & electron & $3.5 \pm 3.7$ & $1.7( \pm 0.9) \times 10^{19}$ \\
\hline
\end{tabular}

Table S5. Chemical compositions including $\mathrm{Sn}^{0}, \mathrm{Sn}^{2+}$, and $\mathrm{Sn}^{4+}$ of $\mathrm{SnO}$ films annealed at 250 ${ }^{\circ} \mathrm{C}$ with different oxygen pressure on 1.9 at\% La loadings, which were de-convoluted from XP spectra of Sn 3d and O 1s.

\begin{tabular}{|c|c|c|c|c|c|c|}
\hline \multirow{2}{*}{$\begin{array}{c}\text { Oxygen } \\
\text { partial } \\
\text { pressure } \\
{[\%]}\end{array}$} & \multicolumn{3}{|c|}{ Sn 3d } & \multicolumn{3}{|c|}{ O 1s } \\
\hline & $\begin{array}{c}\mathrm{Sn}^{4+} \\
(486.4 \\
+\quad 0.3 \mathrm{eV}) \\
\end{array}$ & $\begin{array}{c}\mathrm{Sn}^{2+} \\
(485.7 \\
+0.3 \mathrm{eV}) \\
\end{array}$ & $\begin{array}{c}\mathrm{Sn}^{0} \\
(484.2 \\
\pm \quad 0.3 \mathrm{eV}) \\
\end{array}$ & $\begin{array}{c}O_{\text {chem }} \\
(531.75 \\
\pm 0.2 \mathrm{eV}) \\
\end{array}$ & $\begin{array}{c}\mathrm{O}+\mathrm{Sn}^{4+} \\
(530.25 \\
\pm \quad 0.2 \mathrm{eV}) \\
\end{array}$ & $\begin{array}{c}\mathrm{O}+\mathrm{Sn}^{2+} \\
(529.55 \\
\pm \quad 0.2 \mathrm{eV}) \\
\end{array}$ \\
\hline 3.23 & 15.3 & 81.7 & 3.0 & 3.9 & 17.4 & 78.7 \\
\hline 3.85 & 3.8 & 90.6 & 5.6 & 2.7 & 4.8 & 92.5 \\
\hline 4.46 & 5.9 & 92.2 & 1.9 & 1.1 & 5.3 & 93.6 \\
\hline 5.06 & 5.7 & 90.5 & 3.8 & 1.1 & 9.2 & 89.7 \\
\hline
\end{tabular}




\section{Reference}

(1) Nomura, K.; Kamiya, T.; Hosono, H. Ambipolar Oxide Thin-Film Transistor. Adv. Mater. 2011, 23, 3431-3434.

(2) Han, Y.; Choi, Y.; Jeong, C.; Lee, D.; Song, S.-H.; Kwon, H.-I. Environment-Dependent Bias Stress Stability of $p$-Type SnO Thin-Film Transistors. IEEE Electron Device Lett. 2015, 36, 466-468.

(3) Luo, H.; Liang, L. Y.; Liu, Q.; Cao, H. T. Magnetron-Sputtered SnO Thin Films for $p$ Type and Ambipolar TFT Applications. ECS J. Solid State Sci. Technol. 2014, 3, Q3091-Q3094.

(4) Dhananjay; Chu, C.-W.; Ou, C.-W.; Wu, M.-C.; Ho, Z.-Y.; Ho, K.-C.; Lee, S.-W. Complementary Inverter Circuits Based on $p-\mathrm{SnO}_{2}$ and $n-\mathrm{In}_{2} \mathrm{O}_{3}$ Thin Film Transistors. Appl. Phys. Lett. 2008, 92, 232103.

(5) Ou, C.-W.; Dhananjay; Ho, Z. Y.; Chuang, Y.-C.; Cheng, S.-S.; Wu, M.-C.; Ho, K.-C.; Chu, C.-W. Anomalous $p$-Channel Amorphous Oxide Transistors Based on Tin Oxide and Their Complementary Circuits. Appl. Phys. Lett. 2008, 92, 122113.

(6) Liang, L. Y.; Liu, Z. M.; Cao, H. T.; Yu, Z.; Shi, Y. Y.; Chen, A. H.; Zhang, H. Z.; Fang, Y. Q.; Sun, X. L. Phase and Optical Characterizations of Annealed SnO Thin Films and Their $p$-Type TFT Application. J. Electrochem. Soc. 2010, 157, H598-H602.

(7) Okamura, K.; Nasr, B.; Brand, R. A.; Hahn, H. Solution-Processed Oxide Semiconductor $\mathrm{SnO}$ in $p$-Channel Thin-Film Transistors. J. Mater. Chem. 2012, 22, 4607-4610. 